\title{
Emerging Adults in Inpatient Substance Use Treatment: A Prospective Cohort Study of Patient Characteristics and Treatment Outcomes
}

\author{
Helle Wessel Andersson ${ }^{a} \quad$ Anders D. Forsmo Lauvsnes ${ }^{b, c} \quad$ Trond Nordfjærn $^{a}$ d \\ aDepartment of Research and Development, Clinic of Substance Use and Addiction Medicine, St. Olavs University \\ Hospital, Trondheim, Norway; ${ }^{b}$ Kvamsgrind Addiction Treatment Centre, Trondheim, Norway; ${ }^{c}$ Department of \\ Mental Health, Faculty of Medicine and Health, Norwegian University of Science and Technology, Trondheim, \\ Norway; ${ }^{d}$ Department of Psychology, Norwegian University of Science and Technology, Trondheim, Norway
}

\section{Keywords}

Young adults - Substance use disorders - Patient

characteristics $\cdot$ Residential treatment $\cdot$ Treatment outcome

\begin{abstract}
Introduction: Compared to older adults, emerging adults treated for substance use disorders (SUDs) are more likely to have unfavorable outcomes. However, few studies have investigated the baseline characteristics and treatment outcomes of emerging adults in inpatient SUD treatment. Aims: This study investigated differences in demographic and clinical characteristics and treatment outcomes (relapse or treatment discontinuation) among emerging adult and adult inpatients. Prospective associations between baseline characteristics and unfavorable treatment outcomes were also analyzed across both patient groups. Methods: A prospective cohort study was conducted among inpatients $(n=499)$ at 4 SUD treatment centers in Norway. The sample included emerging adult patients aged $18-25$ years $(n=149)$ and adult patients above 25 years $(n=350)$. Medical records pro-
\end{abstract}

vided data on sociodemographic variables, substance use characteristics, diagnoses, and treatment completion status. Self-reported measures, including age of onset of substance use, motivation, and mental distress, were completed within 2 weeks of admission to treatment. A telephone interview 3 months after discharge provided information about relapses. Results: Emerging adults had a more adverse risk profile in terms of demographic characteristics, clinical variables, and treatment outcomes. Multivariable results showed that polysubstance use and an attention deficit hyperactivity disorder (ADHD) diagnosis were the strongest predictors of unfavorable treatment outcomes for emerging adults. For older adults, only baseline mental distress was a significant predictor of unfavorable treatment outcomes. Conclusions: Treatment and follow-up initiatives could be better tailored for emerging adults. Identification of treatment needs among emerging adults manifesting polysubstance use and ADHD may reduce the likelihood of unfavorable treatment outcomes in this patient group.

(c) 2020 The Author(s)

Published by S. Karger AG, Basel karger@karger.com www.karger.com/ear

Karger $\stackrel{\text { ' }}{5}$

GOPEN ACCESS
C 2020 The Author(s)

Published by S. Karger AG, Basel

This is an Open Access article licensed under the Creative Commons Attribution-NonCommercial-4.0 International License (CC BY-NC) (http://www.karger.com/Services/OpenAccessLicense), applicable to the online version of the article only. Usage and distribution for commercial purposes requires written permission.
Helle Wessel Andersson

Department of Research and Development

Clinic of Substance Use and Addiction Medicine, St. Olavs University Hospital

Sluppen Pb 3250, NO-7006 Trondheim (Norway)

helle.wessel.andersson@stolav.no 


\section{Introduction}

According to population-based surveys, emerging adulthood (18-25 years) $[1,2]$ is the period with the highest prevalence of alcohol and drug use. For instance, 21\% of Americans aged 18-25 years reported having used marijuana in the previous 30 days and 39\% reported binge use of alcohol [3]. The ages between 18 and 25 years are still critical for brain development and maturation, especially with respect to prefrontal regulation of limbic functions, critical to approaching or avoidant behaviors. These are underlying functions for regulating future-oriented behavior and making risky decisions, such as substance abuse [4]. Therefore, this is a period where the use of substances may be particularly harmful [5] especially with respect to psychological dysfunction [4]. Available data from the USA show that among emerging adults, about 1 in 7 has a substance use disorder (SUD) [6] and that this age group represents about $30 \%$ of all patients in specialized SUD treatment [7].

Emerging adults admitted to SUD treatment usually have an early age of substance use onset, typically between 10 and 14 years [8]. Early-onset substance use is associated with a broad array of interrelated risk factors for psychosocial maladjustment $[9,10]$, including attention deficit hyperactivity disorders (ADHD) [11] and other mental health problems [12], lower educational attainment [13], and reduced satisfaction with life [14]. Hence, emerging adults in SUD treatment represent a potentially challenging patient population that may be at increased risk of poor treatment outcomes (e.g., dropout, relapse to substance abuse, or readmissions).

Few studies have investigated the characteristics of the emerging adults who enter inpatient SUD treatment and the factors that are important for their treatment outcomes. The available research comparing emerging adults with older patients in SUD treatment has suggested that emerging adults have distinct characteristics at treatment entry. For example, emerging adults appear to have more behavioral and legal problems, as well as more conflicts with family and close friends [15]. Emerging adults were also more likely to use illicit drugs, especially cannabis, compared with their adult counterparts who were more likely to report alcohol use [15-18]. Moreover, an examination of the prevalence of co-occurring psychiatric disorders in adolescents and adults admitted to SUD treatment [19] suggested that emerging adults were more likely to present with co-occurring mental health and neurodevelopmental problems, particularly ADHD and conduct disorders, compared with older age groups. It

Emerging Adults in Inpatient Substance

Use Treatment has been suggested that baseline perceived stress and psychiatric comorbidity are associated with SUD treatment seekers' motivation to change their substance use behavior [20]. For emerging adults, the motivation for changing their substance use may be an important factor in the establishment of therapeutic alliances [21] and may predict their substance use treatment outcomes [22]. Some studies have found that emerging adults reported being less motivated at treatment entry compared with older adults $[15,16]$; however, others did not find such baseline differences [18].

The few available studies regarding SUD treatment outcomes among emerging adults have also revealed inconsistent results. For instance, both Sinha et al. [16] and Schuman-Olivier et al. [23] suggested that more emerging adults dropped out of SUD treatment and relapsed to substance use compared with older adults. In contrast, Morse and MacMaster [18] found no differences in substance use outcomes between emerging adults and older opiate users following inpatient SUD treatment. In our previous research [24], bivariable results revealed that patients who dropped out of inpatient SUD treatment were more likely to be below 25 years. However, emerging adult age status was not a significant predictor of dropout in multivariable analyses including demographic, substance use, and psychological predictor variables. This finding may reflect that not emerging adult age per se was of relevance for SUD treatment outcome but rather the characteristics associated with emerging adulthood. Although emerging adults may represent a group with higher probability of SUD treatment dropout, relatively few previous studies have investigated the underlying factors that may predict unfavorable treatment outcomes in this group. Moreover, the findings from available research on these issues have limited generalizability owing to the use of selected samples, such as forensic populations [16], opiate users [18], and patients in buprenorphine-assisted treatment [23]. The current study will extend existing research by comparing the characteristics of emerging adults and older adults in inpatient SUD treatment and the impact of baseline psychological and substance use characteristics on SUD treatment outcomes in these 2 subpopulations. The study will contribute to the current literature on emerging adults in SUD treatment and provide important knowledge that may be used to optimize their treatment processes and outcomes. The aims of the current study were as follows.

To compare baseline sociodemographic, psychosocial, and clinical characteristics (e.g., gender, education level, mental distress, motivation, SUD diagnoses, and comor- 
bid mental health disorders) between emerging adults entering inpatient SUD treatment and adult patients. To investigate differences in treatment outcomes between emerging adults and adult patients in terms of proportions with unfavorable (i.e., relapse or treatment discontinuation (dropout)) and favorable treatment outcomes (i.e., no relapse or treatment completion). To analyze prospectively the associations between baseline characteristics and unfavorable treatment outcomes in emerging adults compared to older adults.

\section{Materials and Methods}

\section{Design and Setting}

The data were drawn from a prospective cohort study of patients consecutively admitted to inpatient treatment in 4 public substance use clinics from August 2014 to December 2016. The clinics represent the largest SUD treatment centers in central Norway and cover most of the interdisciplinary specialized treatment approaches provided for the SUD population in this region. The centers provide treatment for people aged 18 years and above with severe substance misuse and polysubstance use. A comprehensive treatment program is provided by a combination of counseling, group, and individual therapy, including milieu and cognitive-behavioral therapies, which are common SUD treatment approaches in Norway and most European countries (European Monitoring Center for Drugs and Drug Addiction, 2014). Patients undergo up to 14 days of detoxification prior to intake if necessary. Inpatient treatment requires patients to abstain from drug and alcohol during the treatment stay; however, because SUD is by nature subject to relapse, patients are generally offered readmittance after adequate detoxification, should they relapse.

Among 598 eligible patients, 93 declined to participate and 2 were not approached due to mental distress. In addition, 4 patients withdrew their consent to participate. The baseline gross sample comprised 499 patients (participation rate, 83\%).

Dedicated research assistants, who had no conflicts of interest related to patient treatment, approached the patients. Patients who agreed to participate gave their informed written consent for follow-up and assessment of their medical records. The participants responded to a standard questionnaire, including validated selfreport measures, 1-2 weeks after intake and at discharge from the unit. The research assistants were available to answer questions during this session. Subsequent follow-up interviews took place by telephone 3 months after discharge. The Regional Ethics Committee of Medical Research in Norway (application \#2013/177) approved the study.

\section{Inclusion Criteria}

The inclusion criteria for the current study were emerging adults and their adult counterparts who were study participants at treatment centers providing treatment for severe substance and polysubstance use. Exclusion criteria were persons judged incapable of giving consent to participate (e.g., due to high levels of mental distress).

\section{Measures}

Demographics

Information about age at treatment intake, gender, and educational attainment was collected from medical records. Education level was categorized as low (10 years primary and secondary education or less $=1$ ) or medium/high (high school/vocational school or more $=0$ ).

\section{Diagnoses}

Medical records were used to collect information about SUD diagnoses (F10-F19) and comorbid psychiatric diagnoses (F20F99) classified according to the International Classification of Diseases-10 (ICD-10) [25].

\section{Substance Use and Treatment History}

A measure of age of onset of substance use was included in the questionnaire filled in at treatment intake, by asking the question "How old were you the first time you used drugs?" Further information about substance use was obtained from medical records. A variable for injecting drug use (yes/no) was based on information about whether the patient had ever injected drugs. Information about having 2 or more SUD diagnoses (F10-F19) was used to construct the polysubstance use variable (yes/no), whereas an illicit drug use variable (yes/no) was based on information about the type of drug used most frequently in the 6 months immediately before admission. Medical records also provided data about any previous SUD inpatient treatment stays.

\section{Motivation}

Baseline motivation was assessed with the Norwegian version [26] of the 5-item motivation subscale of the Circumstances, Motivation, Readiness, and Suitability instrument [27]. The items were answered on a 5-point Likert scale (completely disagree to totally agree), with higher scores indicating stronger intrinsic motivation for changing substance use behavior. The motivation scale had a Cronbach's alpha coefficient ( $\alpha$ ) of 0.82 in the current cohort. The average computed motivation score was used in analyses.

\section{Mental Distress}

Baseline mental distress was measured using the self-reported Hopkins Symptom Checklist-10 [28]. The patients completed the Norwegian version of the 10-item scale [29] to rate how frequently they had experienced symptoms of depression and anxiety during the past 7 days on a 4-point scale from 1 (not at all) to 4 (extremely). The scale had a Cronbach's $\alpha$ of 0.89 in the current cohort. The average score was used in analyses.

Treatment Outcome: Unfavorable or Favorable Outcomes

The treatment outcome measure was a dichotomized score of treatment response as either unfavorable or favorable based on 2 crucial and related outcome measures frequently cited in SUD treatment research: relapse to substance use, for example [30], or treatment dropout [31]. Follow-up interviews 3 months after inpatient treatment provided information about relapse. Patients were defined as having a relapse (i.e., return to regular use) [32] when they reported any drinking or drug use 2 or more times a week during the previous 4 weeks or being readmitted to SUD treatment (see also [33]). Information about dropout, defined as premature termination of the planned inpatient program (yes/no) [24], was collected from the medical records. Patients were as- 
Table 1. Demographic and baseline characteristics in emerging adults and adults

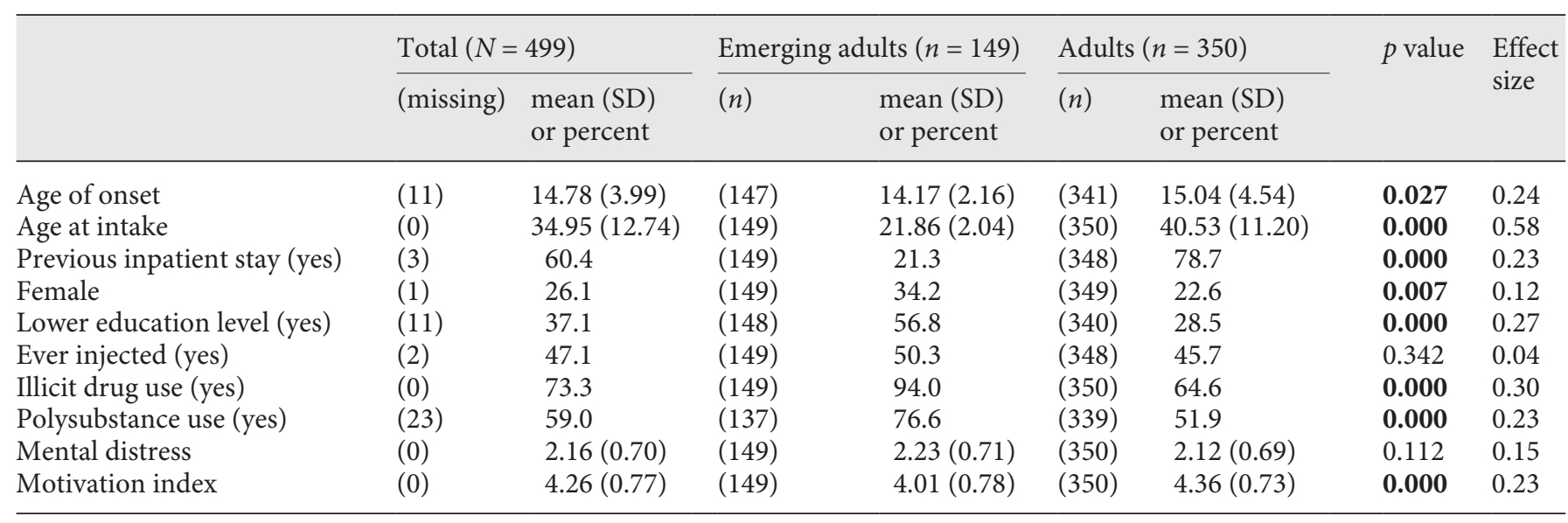

Significant $p$ values $(<0.05)$ are in bold.

signed an outcome score of 1 (unfavorable) if they had relapsed to substance use or 0 (favorable) if they reported no relapse at followup. Among patients lost to follow-up, those who completed treatment were included in the favorable outcome category, whereas those who dropped out of treatment were included in the unfavorable treatment category.

\section{Statistical Analyses}

The statistical procedures were performed using IBM SPSS Statistics (version 23; IBM SPSS, Armonk, NY, USA). Proportion tests and independent samples $t$ tests were conducted to compare emerging adults and adult patients on the following variables: (1) demographic and baseline characteristics (i.e., substance use, mental distress, and motivation), (2) prevalence of SUD diagnoses and comorbid psychiatric diagnoses, and (3) treatment outcome status. Effect sizes were calculated using Cohen's $d$ or Cramér's V. To address the third aim of the study, that is, to analyze the associations between baseline characteristics and unfavorable treatment outcomes in emerging adults compared to older adults, univariate predictors were first entered in separate binary logistic regression models with unfavorable treatment outcomes (yes/no) as the dependent variable. Next, predictors from the first step that were significantly ( $p$ value $\leq 0.10$ ) associated with the outcome were entered simultaneously into a multivariable logistic regression model. A treatment center variable was entered as a covariate to adjust for the effect of long-term versus short-term treatment stay $(1 / 0)$. The analyses were performed separately for emerging adults and older adults to illuminate any differences in predictor variables between the 2 samples. Variance inflation scores ranged from 1.063 to 1.437 indicating that multicollinearity was not an issue [34].

\section{Sensitivity Analysis}

To assess any potential bias due to missing data on treatment outcome at 3-month follow-up (relapse/no relapse), multiple imputations with the fully conditional specification method were performed.

Emerging Adults in Inpatient Substance Use Treatment

\section{Results}

\section{Sample}

In total, 499 patients fulfilled the inclusion criteria (see flowchart of the study sample in online suppl. Figure; see www.karger.com/doi/10.1159/000512156 for all online suppl. material), of whom 149 were emerging adult patients (age 18-25 years) and 350 were adult patients $(>25$ years) (online suppl. Table shows the characteristics of the treatment sites and number of patients by site).

\section{Sociodemographic and Psychosocial Characteristics among Emerging Adults and Adults}

As shown in Table 1, there was a higher proportion of females $(34 \%)$ in the emerging adult sample than in the adult sample (23\%). The emerging adults were also more likely to have low education (57\%) compared with adults (29\%). There were more illicit drug users (94\%) and more polysubstance users (77\%) among emerging adults than among adults (65 and 52\%, respectively). There were no significant differences in substance injection history between the 2 groups. The emerging adults had a younger age of onset of substance use than adults and were less likely $(21 \%)$ than adults $(79 \%)$ to have previous inpatient stays. Emerging adults reported overall lower treatment motivation than their older counterparts.

\section{Clinical Characteristics of Emerging Adults Compared with Adults}

Clinical characteristics in the 2 samples reflected that emerging adults were less likely to have a past-year alco- 
Table 2. Prevalence of past-year substance use diagnoses and other psychiatric diagnoses in emerging adults and adults

\begin{tabular}{|c|c|c|c|c|c|c|}
\hline Diagnoses & $(N=499), n$ & $\begin{array}{l}\text { Emerging adults } \\
(n=149), \%\end{array}$ & $\begin{array}{l}\text { Adults } \\
(n=350), \%\end{array}$ & $x^{2}$ & $p$ value & Effect size \\
\hline Alcohol (F10) & 239 & 32.1 & 57.5 & 25.19 & 0.000 & 0.23 \\
\hline Opioids (F11) & 108 & 21.2 & 23.3 & 0.25 & 0.614 & 0.02 \\
\hline Cannabis (F12) & 213 & 74.5 & 32.7 & 68.65 & 0.000 & 0.38 \\
\hline Sedatives (F13) & 164 & 42.3 & 31.3 & 5.29 & 0.021 & 0.11 \\
\hline Cocaine (F14) & 20 & 7.3 & 2.9 & 4.59 & 0.032 & 0.10 \\
\hline Stimulants (F15) & 188 & 54.0 & 33.6 & 16.97 & 0.000 & 0.19 \\
\hline Hallucinogens (F16) & 11 & 6.6 & 0.6 & 15.45 & 0.000 & 0.18 \\
\hline Multiple drugs (F19) & 33 & 10.2 & 5.6 & 3.22 & 0.073 & 0.08 \\
\hline Affective disorders (F30-39) & 92 & 21.5 & 17.1 & 1.31 & 0.253 & 0.05 \\
\hline Anxiety disorders (F40-48) & 133 & 30.9 & 24.9 & 1.93 & 0.164 & 0.06 \\
\hline Personality disorders (F60-69) & 66 & 12.1 & 13.7 & 0.24 & 0.622 & 0.02 \\
\hline ADHD (F90) & 75 & 24.2 & 11.1 & 13.87 & 0.000 & 0.17 \\
\hline Other psychiatric disorders & 49 & 13.4 & 8.3 & 3.11 & 0.078 & 0.08 \\
\hline Any mental disorder ${ }^{a}$ & 265 & 63.8 & 48.6 & 9.68 & 0.002 & 0.14 \\
\hline
\end{tabular}

ADHD, attention deficit hyperactivity disorder. Significant $p$ values $(<0.05)$ are in bold. ${ }^{\text {a }}$ The most prevalent past-year comorbid mental disorders were affective disorders and anxiety disorders.

Table 3. Treatment outcomes in emerging adults and adults

\begin{tabular}{|c|c|c|c|c|c|c|c|}
\hline \multirow[t]{2}{*}{ Treatment outcomes } & \multicolumn{2}{|c|}{$\begin{array}{l}\text { Emerging adults } \\
(n=149)\end{array}$} & \multicolumn{2}{|c|}{$\begin{array}{l}\text { Adults } \\
(n=350)\end{array}$} & \multirow[t]{2}{*}{$\chi^{2}$} & \multirow[t]{2}{*}{$p$ value } & \multirow[t]{2}{*}{$\begin{array}{l}\text { Effect } \\
\text { size }\end{array}$} \\
\hline & $n$ & $\%$ & $n$ & $\%$ & & & \\
\hline \multicolumn{8}{|l|}{ Unfavorable } \\
\hline Relapse at follow-up & 43 & 28.9 & 77 & 22.0 & 2.69 & 0.100 & 0.07 \\
\hline Treatment dropout/not retained ${ }^{\mathrm{a}}$ & 25 & 16.8 & 31 & 8.9 & 6.58 & 0.010 & 0.12 \\
\hline \multicolumn{8}{|l|}{ Favorable } \\
\hline No relapse at follow-up & 48 & 32.3 & 173 & 49.4 & 12.55 & 0.000 & 0.16 \\
\hline Completed treatment/not retained ${ }^{\mathrm{b}}$ & 33 & 22.1 & 69 & 19.7 & 0.38 & 0.537 & 0.03 \\
\hline
\end{tabular}

The number of patients with unfavorable outcomes was statistically higher among emerging adults (45.7\%) than adults $(30.9 \%)(p=0.000, V=0.142)$. Significant $p$ values $(<0.05)$ are in bold. ${ }^{\text {a }}$ The baseline characteristics for emerging adults who dropped out/not retained for follow-up were similar to those of emerging adults who relapsed at follow-up. Adults who dropped out/were not retained for follow-up were younger at intake $(p<0.05)$ and more likely to have a diagnosis of affective disorders than adults who relapsed at follow-up. ${ }^{\mathrm{b}}$ Emerging adults who completed treatment/not retained for follow-up were more likely to have lower education $(p=0.042)$ and more likely to be men $(p=0.048)$ than emerging adults who did not relapse at follow-up. Adults who completed treatment/not retained for follow-up were more likely to be younger at intake $(p<0.05)$ than adults who did not relapse at follow-up.

hol use disorder (58 vs. $32 \%$ ) and more likely to have a wide range of past-year illicit drug use disorders than the adult group (Table 2). The strongest effect sizes for differences in past-year illicit drug use disorders were found for cannabis ( 75 vs. $33 \%$ ), stimulants (54 vs. $34 \%$ ), and seda- tives (42 vs. $31 \%$ ). Emerging adults were also more likely to have a past-year mental disorder (64 vs. $49 \%$ ), and there were more patients diagnosed with $\mathrm{ADHD}$ in the emerging adults' group (24 vs. 11\%). 
Table 4. Predictors of treatment outcome in EA and A

\begin{tabular}{|c|c|c|c|c|c|c|c|}
\hline \multirow[t]{2}{*}{ Baseline variables } & \multirow[t]{2}{*}{ Sample } & \multicolumn{3}{|c|}{ Univariate models } & \multicolumn{3}{|c|}{ Multivariate model ${ }^{\mathrm{a}}$} \\
\hline & & OR & $95 \% \mathrm{CI}$ & $p$ value & OR & $95 \%$ CI & $p$ value \\
\hline \multirow[t]{2}{*}{ Age of onset } & EA & 0.93 & $0.80 ; 1.09$ & 0.382 & & & \\
\hline & A & 0.95 & $0.89 ; 1.02$ & 0.156 & & & \\
\hline \multirow[t]{2}{*}{ Age at intake } & EA & 0.87 & $0.74 ; 1.03$ & 0.100 & 0.90 & $0.75 ; 1.07$ & 0.219 \\
\hline & A & 0.98 & $0.96 ; 1.00$ & 0.041 & 0.99 & $0.97 ; 1.01$ & 0.419 \\
\hline \multirow[t]{2}{*}{ Previous inpatient stay } & EA & 1.22 & $0.64 ; 2.34$ & 0.552 & & & \\
\hline & A & 1.44 & $0.87 ; 2.38$ & 0.154 & & & \\
\hline \multirow[t]{2}{*}{ Female } & EA & 0.76 & $0.38 ; 1.51$ & 0.431 & & & \\
\hline & A & 0.98 & $0.57 ; 1.70$ & 0.951 & & & \\
\hline \multirow[t]{2}{*}{ Lower education } & EA & 1.39 & $0.72 ; 2.69$ & 0.322 & & & \\
\hline & A & 1.73 & $1.05 ; 2.84$ & 0.031 & 1.42 & $0.84 ; 2.40$ & 0.189 \\
\hline \multirow[t]{2}{*}{ Illicit drug use } & EA & 3.12 & $0.63 ; 15.56$ & 0.165 & & & \\
\hline & A & 1.29 & $0.80 ; 2.09$ & 0.303 & & & \\
\hline \multirow[t]{2}{*}{ Ever injected } & EA & 1.68 & $0.88 ; 3.22$ & 0.118 & & & \\
\hline & $\mathrm{A}$ & 1.69 & $1.07 ; 2.66$ & 0.025 & 1.20 & $0.72 ; 2.01$ & 0.479 \\
\hline \multirow[t]{2}{*}{ Polysubstance use } & EA & 2.51 & $1.06 ; 5.93$ & 0.036 & 3.08 & $1.22 ; 7.44$ & 0.017 \\
\hline & A & 1.39 & $0.88 ; 2.21$ & 0.162 & & & \\
\hline \multirow[t]{2}{*}{ Mental distress } & EA & 1.28 & $0.81 ; 2.03$ & 0.292 & & & \\
\hline & A & 1.74 & $1.25 ; 2.43$ & 0.001 & 1.63 & $1.15 ; 2.32$ & 0.006 \\
\hline \multirow[t]{2}{*}{ Motivation } & EA & 0.85 & $0.56 ; 1.28$ & 0.424 & & & \\
\hline & A & 0.83 & $0.62 ; 1.12$ & 0.223 & & & \\
\hline \multirow[t]{2}{*}{ Affective disorders } & EA & 0.55 & $0.24 ; 1.25$ & 0.152 & & & \\
\hline & A & 1.26 & $0.70 ; 2.26$ & 0.446 & & & \\
\hline \multirow[t]{2}{*}{ Anxiety } & EA & 0.78 & $0.38 ; 1.57$ & 0.478 & & & \\
\hline & A & 1.12 & $0.69 ; 1.96$ & 0.564 & & & \\
\hline \multirow[t]{2}{*}{ Personality } & EA & 1.22 & $0.46 ; 3.27$ & 0.692 & & & \\
\hline & A & 1.72 & $0.67 ; 2.41$ & 0.462 & & & \\
\hline \multirow[t]{2}{*}{ ADHD } & EA & 2.29 & $1.06 ; 4.93$ & 0.035 & 3.20 & $1.35 ; 7.59$ & 0.009 \\
\hline & A & 2.33 & $1.21 ; 4.65$ & 0.012 & 1.99 & $0.98 ; 4.06$ & 0.059 \\
\hline \multirow[t]{2}{*}{ Treatment site } & EA & 0.74 & $0.38 ; 1.42$ & 0.360 & 0.64 & $0.30 ; 1.35$ & 0.241 \\
\hline & A & 0.78 & $0.40 ; 1.50$ & 0.449 & 0.73 & $0.36 ; 1.47$ & 0.374 \\
\hline
\end{tabular}

EA, emerging adults; A, adults; OR, odds ratio; CI, confidence interval; ADHD, attention deficit hyperactivity disorder; EA, Nagelkerke $R^{2}=0.129$, Cox and Snell $R^{2}=0.096, N=137$; A, Nagelkerke $R^{2}=0.085$, Cox and Snell $R^{2}=0.060, N=339$. Significant $p$ values $(<0.05)$ are in bold. ${ }^{a}$ Results of multivariable logistic regression analysis including variables with $p<0.10$ in bivariable analysis.

Treatment Outcomes of Emerging Adults Compared with Adults

Emerging adults were substantially more likely to have overall unfavorable treatment outcomes (46\%) than adults (31\%) (Table 3). Emerging adults were significantly less likely to report no relapse at follow-up (32\%) compared with adults (49\%). Emerging adults were more like- ly to be in the dropout/not retained follow-up group (17 vs. 9\%).

\section{Predictors of Treatment Outcome}

The results of univariate and multivariable analyses of factors associated with treatment outcome in emerging adults and older adults are shown in Table 4. The uni- 
variate models showed that in both samples, factors that conferred heightened probability of unfavorable treatment outcome included younger age at intake and having an ADHD diagnosis. In addition, for emerging adults, baseline polysubstance use increased the likelihood of an unfavorable outcome. For older adults, univariate predictors included lower education level, having ever injected drugs, and higher mental distress. The multivariable analysis showed that for emerging adults, polysubstance use and having an ADHD diagnosis uniquely contributed to the prediction of an unfavorable treatment, each factor associated with more than a 3 -fold risk of an unfavorable treatment outcome $(\mathrm{OR}=3.06$ and $\mathrm{OR}=3.12$, respectively). For the older adult sample, only mental distress remained a significant predictor of unfavorable treatment outcome in the multivariable model.

\section{Sensitivity Analysis}

The results of multivariable analysis conducted on the multiple imputed dataset showed that for emerging adults, an unfavorable treatment outcome was predicted by having ever injected drugs $(\mathrm{OR}=2.22,95 \% \mathrm{CI}=1.10$; $4.49, p=0.026)$, higher mental distress ( $\mathrm{OR}=1.67,95 \%$ $\mathrm{CI}=1.00 ; 2.77, p=0.049)$, and having an ADHD diagnosis $(\mathrm{OR}=2.80,95 \% \mathrm{CI}=1.18 ; 6.63, p=0.019)$. For adults, an unfavorable treatment outcome was predicted by having a lower educational attainment $(\mathrm{OR}=1.69,95 \% \mathrm{CI}=$ $1.01 ; 2.83, p=0.045)$, age at intake $(\mathrm{OR}=0.97,95 \% \mathrm{CI}=$ $0.95 ; 1.00, p=0.036)$, higher mental distress $(\mathrm{OR}=1.41$, $95 \% \mathrm{CI}=1.00 ; 1.99 . p=0.049$ ), and treatment site (short term $)(\mathrm{OR}=0.44,95 \% \mathrm{CI}=0.21 ; 0.90, p=0.024)$.

\section{Discussion/Conclusion}

Overall, the current results showed that emerging adults had a more severe risk profile compared with adult patients and were more likely to experience unfavorable clinical outcomes. Polysubstance use and ADHD were important predictors of unfavorable outcome among emerging adults. For adults, mental distress was the only baseline predictor of treatment outcome.

The ratio of females to males was higher in the emerging adult sample than in the adult sample. This finding is consistent with previous research showing that females referred to SUD treatment are younger than males [35], which may reflect gender differences in substance use initiation, patterns of use, and rapidity of progression of SUD [36]. Among emerging adults, the mean age of first substance use was 14 years, which falls within the range of 10-14 years at age of onset reported by Dennis et al. [8]. This estimate is also similar to that reported in the outpatient sample by Sinha et al. [16]. The earlier age of onset of substance use among emerging adults compared with their adult counterparts aligns with the results of previous research in SUD treatment settings [16, 23].

More than half of the current emerging adult sample did not complete high school, and the number of emerging adult patients with low educational achievement was considerably higher than in the adult sample. Hence, it is plausible that low educational achievement was related to early onset of substance use and underlying common prior causes, such as other deviant behaviors and adverse psychosocial factors $[37,38]$ and intellectual disabilities [39]. The elevated prevalence of ADHD among emerging adults concords with its estimated prevalence in the general adult population [40] and may be explained by symptoms declining with age [41] and/or underdiagnosing of ADHD in older adults [42].

In line with previous studies that compared the substance use profiles of emerging adults and older patients in SUD treatment $[16,18,23]$, use of illicit substances was more prevalent among emerging adults and nearly 3 of 4 were multiple substance users. Polysubstance use may be a means of enhancing the effect of one drug or accentuating the perceived benefits of each drug [43] or managing the adverse effects of one drug. For those who become dependent on substances at an early age, there may also be an increased risk of polysubstance use owing to early socialization into environments with favorable attitudes toward the use of more than one drug [44].

The baseline differences in intrinsic motivation between emerging adults and adults, which indicated that emerging adults were less motivated to change their substance use behavior, are consistent with prior research on outpatient samples [16]. However, the findings contrast with Morse and MacMaster's [18] study of emerging adult opiate users. The comparison between studies of emerging adults' baseline motivation is problematic owing to the use of different samples in different treatment settings and different measures of motivation.

In addition to their more adverse risk profile in terms of demographic and clinical characteristics, emerging adults were more likely to have unfavorable treatment outcomes. This finding aligns with reports from previous research of higher dropout rates [24] and an increased risk of relapse among emerging adults compared with older patients in SUD outpatient programs [16, 23]. As more treatment is associated with better treatment outcomes [45], the current result may to some extent be ex- 
plained by emerging adults having fewer inpatient treatment stays than adult patients (about $80 \%$ of emerging adults did not have a previous inpatient stay vs. $22 \%$ of adult patients). Nonetheless, the current findings demonstrate the importance of considering possible unique inpatient SUD treatment needs among patients aged 18-25 years, including any need for reinforced treatment interventions.

The current analysis performed separately for emerging adults and older adults revealed some differences in predictor variables between the 2 subsamples. For emerging adults, the most prominent predictors of unfavorable treatment outcomes were polysubstance use and an ADHD diagnosis. Polysubstance use may indicate a more severe drug use profile [46], and it is associated with increased mental health and physical problems [43]. It has also been identified as an important prognostic factor for unfavorable treatment trajectories in previous work [47, 48]. The current study extends these findings to emerging adults in inpatient treatment. ADHD is characterized by impaired attention and varying degrees of impulsivity and may lead to high activation levels in emerging adults; all of these factors may reduce patients' benefit from treatment interventions $[49,50]$. ADHD as a clinical concept has several subtypes (inattentive and hyperactive/ impulsive). The degree of ADHD symptoms is also related to the degree of executive functioning problems [51], which in turn has specific relationships with the probability of sustained abstinence or relapse [52]. In the current study, ADHD was registered as a discrete diagnosis, and thus the nuances of the diagnosis were not represented in the analyses. Higher baseline mental distress predicted treatment outcome among older adults but not for emerging adults. The negative impact of higher baseline symptoms of anxiety and depression on SUD treatment outcomes has been repeatedly reported $[24,53,54]$. The present results suggest that for emerging adults, treatment outcome might be more strongly affected by externalizing behavior problems.

\section{Limitations}

The study has some limitations that should be considered. The current measure of treatment outcome was based on patients' reports of relapse at the 3-month follow-up, supplied with information about treatment completion status at discharge. Based on previous research suggesting that treatment completion is associated with favorable outcomes $[53,55]$, patients lost to follow-up (32\%) who completed treatment were categorized as having a favorable treatment outcome, whereas those who dropped out of treatment were defined as having an unfavorable treatment outcome. Complete follow-up data on substance use behaviors could have changed the distribution of the patients in the 2 categories. For example, additional analyses showed that among emerging adults in the favorable outcome category, treatment completers who were not retained for follow-up were more likely to have lower education and to be male than those who were retained and reported no relapse. Although those who were lost for follow-up were similar to those who were retained on most baseline variables, including substance use characteristics, we cannot rule out the possibility that the current results might have been slightly different if they had been based on measures of relapse status in a complete study sample. The results of the sensitivity analyses indicated that there are some uncertainties associated with the identification of predictor variables for SUD treatment outcomes. However, the results of this additional analysis supported the impact of ADHD on treatment outcomes among emerging adults.

There is some uncertainty regarding the accuracy of the self-reported measure of age of first substance use in the present study because of the possible recall bias of retrospective reports [56]. However, longitudinal studies have suggested adequate test-retest reliability of self-reported age of first onset of substance use [57].

In addition, a limited set of possible predictor variables was available for the current analysis, including detailed information on polysubstance use and severity of dependence. It is important to note that the current measure of polysubstance use was based on information from the medical record about having 2 or more ICD-10 SUD diagnoses, which may not meet the multiple substance dependence criteria for ICD-10 diagnosis F19 (chaotic intake of multiple substances).

Moreover, the inclusion of treatment-related factors, such as measures of type and intensity of pre-inpatient treatment efforts and aspects of the therapeutic relationship, would have provided more knowledge relevant to the development of preventive measures. Moreover, intellectual disability may be an important factor in the ability to profit from many SUD treatment modalities. In this study, inferences about intellectual functioning were made from the proxy variable academic achievement, but low school completion status may have other explanations than low intellectual functioning per se, possibly obscuring the importance of intellectual functioning on treatment outcome. 


\section{Conclusions}

The more adverse risk profile for psychosocial maladjustment and severe substance misuse among emerging adults compared with adults, accompanied by poorer treatment outcomes, may prompt greater differentiation between age groups in inpatient treatment. It is possible that emerging adults do not benefit from receiving similar interventions to those of adults. Identification of the treatment needs of emerging adults manifesting polysubstance use and ADHD may reduce the likelihood of unfavorable treatment outcomes in this patient group. These factors may hamper progress in inpatient treatment and need to be detected at an early stage in the pretreatment phase. Finally, further research should look into changes in dynamic factors such as cognitive functions and mental health and how they continuously interact to produce a moment-to-moment risk profile for each patient.

\section{Acknowledgements}

We want to thank the research assistants of the participating clinics for their contribution to the implementation of the study. We also want to thank the patients for their contribution to this research.

\section{Statement of Ethics}

The study protocol was approved by the Regional Ethics Committee of Medical Research in Norway (\#2013/177), and all procedures performed were in accordance with the 1964 Helsinki Declaration and its later amendments. Informed written consent was obtained from all individual participants in the study.

\section{Conflict of Interest Statement}

The authors have no conflicts of interest to declare.

\section{Funding Sources}

Funding for this study was provided by the Norwegian University of Science and Technology (NTNU), Trondheim, Norway, St. Olav's University Hospital, Trondheim, Norway, and Møre and Romsdal Hospital Trust, Ålesund, Norway.

\section{Author Contributions}

H.W.A.: idea and design, methodology, writing - original draft preparation, and final edits. A.D.F.L.: writing - reviewing. T.N.: supervision and writing - reviewing.

\section{References}

1 Arnett JJ. Emerging adulthood: a theory of development from the late teens through the twenties. Am Psychol. 2000;55:469-80.

2 Arnett JJ. Emerging adulthood(s): the cultural psychology of a new life stage: new syntheses in theory, research and policy. In: Jensen LA, editor. Bridging cultural and developmental psychology: new syntheses in theory, research, and policy. New York: Oxford University Press; 2011. p. 255-75.

3 Baumer PC, Dennis ML, Estrada B. Needs, services received, and outcomes of adolescents and young adults in substance use disorder treatment. In: Leukefeld CG, Gullotta $\mathrm{TP}$, editors. Adolescent substance abuse, issues in children's and families' lives. Cham, Switzerland: Springer; 2018. p. 67-139.

4 Taber-Thomas B, Perez-Edgar K. Emerging adulthood brain development. In: Arnett JJ, editor. The Oxford handbook of emerging adulthood. New York, NY: Oxford University Press; 2016. p. 126-41.

5 Guerri C, Pascual M. Mechanisms involved in the neurotoxic, cognitive, and neurobehavioral effects of alcohol consumption during adolescence. Alcohol. 2010;44(1):15-26.
6 SAMHSA. Key substance use and mental health indicators in the United States: results from the 2017 National Survey on Drug Use and Health. Rockville, MD: Substance Abuse and Mental Health Services Administration; 2018.

7 SAMHSA. Treatment Episode data set 20022012: national admissions to substance abuse treatment services. Rockville, MD: Substance Abuse and Mental Health Services Administration; 2014.

8 Dennis ML, White MK, Ives ML. Individual characteristics and needs associated with substance misuse of adolescents and young adults in addiction treatment. In: Leukefeld C, Gullotta T, Staton Tindall M, editors. Handbook on adolescent substance abuse prevention and treatment: evidence-based practice. New London, CT: Child and Family Agency Press; 2009. p. 45-72.

9 Fergusson DM, Lynskey MT, Horwood LJ. The short-term consequences of early onset cannabis use. J Abnorm Child Psychol. 1996; 24(4):499-512.

10 Behrendt S, Wittchen HU, Höfler M, Lieb R, Beesdo K. Transitions from first substance use to substance use disorders in adolescence: is early onset associated with a rapid escalation? Drug Alcohol Depend. 2009;99(1-3): 68-78.
11 Groenman AP, Oosterlaan J, Rommelse N, Franke B, Roeyers H, Oades RD, et al. Substance use disorders in adolescents with attention deficit hyperactivity disorder: a 4 -year follow-up study. Addiction. 2013;108(8): 1503-11.

12 Armstrong TD, Costello EJ. Community studies on adolescent substance use, abuse, or dependence and psychiatric comorbidity. J Consult Clin Psychol. 2002;70(6):1224.

13 Silins E, Horwood LJ, Patton GC, Fergusson DM, Olsson CA, Hutchinson DM, et al. Young adult sequelae of adolescent cannabis use: an integrative analysis. Lancet Psychiatry. 2014;1(4):286-93.

14 Zullig KJ, Valois RF, Huebner ES, Oeltmann JE, Drane JW. Relationship between perceived life satisfaction and adolescents' substance abuse. J Adolesc Health. 2001;29(4): 279-88.

15 Morse SA, MacMaster S. Characteristics and outcomes of college-age adults enrolled in private residential treatment: implications for practice. J Soc Work Pract Addict. 2014;14(1): 6-26.

16 Sinha R, Easton C, Kemp K. Substance abuse treatment characteristics of probation-referred young adults in a community-based outpatient program. Am J Drug Alcohol Abuse. 2003;29(3):585-97. 
17 Schuman-Olivier Z, Claire Greene M, Bergman BG, Kelly JF. Is residential treatment effective for opioid use disorders? A longitudinal comparison of treatment outcomes among opioid dependent, opioid misusing, and non-opioid using emerging adults with substance use disorder. Drug Alcohol Depend. 2014;144:178-85.

18 Morse S, MacMaster S. Characteristics and outcomes of young adult opiate users receiving residential substance abuse treatment. J Evid Inf Soc Work. 2015;12(6):556-66.

19 Chan YF, Dennis ML, Funk RR. Prevalence and comorbidity of major internalizing and externalizing problems among adolescents and adults presenting to substance abuse treatment. J Subst Abuse Treat. 2008;34(1): $14-24$.

20 DiClemente CC, Doyle SR, Donovan D. Predicting treatment seekers' readiness to change their drinking behavior in the COMBINE study. Alcohol Clin Exp Res. 2009;33(5):879-92.

21 Urbanoski KA, Kelly JF, Hoeppner BB, Slaymaker V. The role of therapeutic alliance in substance use disorder treatment for young adults. J Subst Abuse Treat. 2012;43(3):344-51.

22 Kelly JF, Urbanoski KA, Hoeppner BB, Slaymaker V. "Ready, willing, and (not) able" to change: young adults' response to residential treatment. Drug Alcohol Depend. 2012; 121(3):224-30

23 Schuman-Olivier Z, Weiss RD, Hoeppner BB, Borodovsky J, Albanese MJ. Emerging adult age status predicts poor buprenorphine treatment retention. J Subst Abuse Treat. 2014; 47(3):202-12.

24 Andersson HW, Steinsbekk A, Walderhaug E, Otterholt E, Nordfjærn T. Predictors of dropout from inpatient substance use treatment: a prospective cohort study. Subst Abuse. 2018;12:1178221818760551.

25 World Health Organization (WHO). The ICD10 classification of mental and behavioral disorders: clinical descriptions and diagnostic guidelines. Geneva, Switzerland: World Health Organization; 1992.

26 Ravndal E, Andresen AS. Ytre omstendigheter, motivasjon og forberedthet ved behandling av rusmiddelbruk. Oslo, Norway: Norwegian Institute for Alcohol and Drug Research (SIRUS); 2006.

27 Leon GD, Melnick G, Kressel D, Jainchill N. Circumstances, motivation, readiness, and suitability (the CMRS Scales): predicting retention in therapeutic community treatment. Am J Drug Alcohol Abuse. 1994;20(4):495515.

28 Derogatis LR, Lipman RS, Rickels K, Uhlenhuth EH, Covi L. The Hopkins symptom checklist (HSCL): a self-report symptom inventory. Behav Sci. 1974;19(1):1-15.

29 Strand BH, Dalgard OS, Tambs K, Rognerud M. Measuring the mental health status of the Norwegian population: a comparison of the instruments SCL-25, SCL-10, SCL-5 and MHI-5 (SF-36). Nord J Psychiatry. 2003; 57(2):113-8.
30 Bradizza CM, Stasiewicz PR, Paas ND. Relapse to alcohol and drug use among individuals diagnosed with co-occurring mental health and substance use disorders: a review. Clin Psychol Rev. 2006;26(2):162-78.

31 Brorson HH, Ajo Arnevik E, Rand-Hendriksen K, Duckert F. Drop-out from addiction treatment: a systematic review of risk factors. Clin Psychol Rev. 2013;33(8):1010-24.

32 Hendershot CS, Witkiewitz K, George WH, Marlatt GA. Relapse prevention for addictive behaviors. Subst Abuse Treat Prev Policy. 2011;6(1):17.

33 Bernstein J, Derrington TM, Belanoff C, Cabral HJ, Babakhanlou-Chase H, Diop H, et al. Treatment outcomes for substance use disorder among women of reproductive age in Massachusetts: a population-based approach. Drug Alcohol Depend. 2015;147:151-9.

34 Hair J, Anderson R, Tatham R, Black W. Multivariate data analysis. 3rd ed. New York: Macmillian; 1995.

35 Green CA, Polen MR, Dickinson DM, Lynch FL, Bennett MD. Gender differences in predictors of initiation, retention, and completion in an HMO-based substance abuse treatment program. J Subst Abuse Treat. 2002; 23(4):285-95

36 Greenfield SF, Back SE, Lawson K, Brady KT. Substance abuse in women. Psychiatr Clin North Am. 2010;33(2):339-55.

37 Fergusson DM, Horwood LJ, Beautrais AL. Cannabis and educational achievement. Addiction. 2003;98(12):1681-92.

38 Bachman JG, Schulenberg JE, Freedman-Doan P, Messersmith EE, O’Malley PM, Johnston LD. The education-drug use connection: how successes and failures in school relate to adolescent smoking, drinking, drug use, and delinquency. Psychology Press; 2008.

39 Salavert J, Clarabuch A, Fernández-Gómez MJ, Barrau V, Giráldez MP, Borràs J. Substance use disorders in patients with intellectual disability admitted to psychiatric hospitalisation. J Intellect Disabil Res. 2018;62(11):923-30.

40 de Zwaan M, Gruss B, Müller A, Graap H, Martin A, Glaesmer H, et al. The estimated prevalence and correlates of adult ADHD in a German community sample. Eur Arch Psychiatry Clin Neurosci. 2012;262(1):79-86.

41 Bitter I, Simon V, Bálint S, Mészáros A, Czobor P. How do different diagnostic criteria, age and gender affect the prevalence of attention deficit hyperactivity disorder in adults? An epidemiological study in a Hungarian community sample. Eur Arch Psychiatry Clin Neurosci. 2010;260(4):287-96.

42 Ginsberg Y, Quintero J, Anand E, Casillas M, Upadhyaya HP. Underdiagnosis of attentiondeficit/hyperactivity disorder in adult patients: a review of the literature. Prim Care Companion CNS Disord. 2014;16(3): PCC.13r01600.

43 Connor JP, Gullo MJ, White A, Kelly AB. Polysubstance use: diagnostic challenges, patterns of use and health. Curr Opin Psychiatry. 2014;27(4):269-75.
44 Hall WD, Lynskey M. Is cannabis a gateway drug? Testing hypotheses about the relationship between cannabis use and the use of other illicit drugs. Drug Alcohol Rev. 2005;24(1): 39-48.

45 Teesson M, Ross J, Darke S, Lynskey M, Ali R, Ritter A, et al. One year outcomes for heroin dependence: findings from the Australian Treatment Outcome Study (ATOS). Drug Alcohol Depend. 2006;83(2):174-80.

46 Moss HB, Chen CM, Yi HY. Early adolescent patterns of alcohol, cigarettes, and marijuana polysubstance use and young adult substance use outcomes in a nationally representative sample. Drug Alcohol Depend. 2014;136:5162.

47 Trenz RC, Scherer M, Harrell P, Zur J, Sinha A, Latimer W. Early onset of drug and polysubstance use as predictors of injection drug use among adult drug users. Addict Behav. 2012;37(4):367-72.

48 Burdzovic Andreas J, Lauritzen G, Nordfjaern T. Co-occurrence between mental distress and poly-drug use: a ten year prospective study of patients from substance abuse treatment. Addict Behav. 2015;48:71-8.

49 Levin FR, Evans SM, Vosburg SK, Horton T, Brooks D, Ng J. Impact of attention-deficit hyperactivity disorder and other psychopathology on treatment retention among cocaine abusers in a therapeutic community. Addict Behav. 2004;29(9):1875-82.

50 Mariani JJ, Levin FR. Treatment strategies for co-occurring ADHD and substance use disorders. Am J Addict. 2007;16(Suppl 1):45-6.

51 Silverstein MJ, Faraone SV, Leon TL, Biederman J, Spencer TJ, Adler LA. The relationship between executive function deficits and Dsm5-defined ADHD symptoms. J Atten Disord. 2020;24(1):41-51.

52 Lauriola M, Panno A, Levin IP, Lejuez CW. Individual differences in risky decision making: a meta-analysis of sensation seeking and impulsivity with the balloon analogue risk task. J Behav Decis Mak. 2014;27(1):20-36.

53 Andersson HW, Wenaas M, Nordfjærn T. Relapse after inpatient substance use treatment: a prospective cohort study among users of illicit substances. Addict Behav. 2019;90: 222-8.

54 Erga AH, Hønsi A, Anda-Ågotnes LG, Nesvåg $\mathrm{S}$, Hesse $\mathrm{M}$, Hagen $\mathrm{E}$. Trajectories of psychological distress during recovery from polysubstance use disorder. Addict Res Theory. 2020:1-8.

55 Gossop M, Stewart D, Browne N, Marsden J. Factors associated with abstinence, lapse or relapse to heroin use after residential treatment: protective effect of coping responses. Addiction. 2002;97(10):1259-67.

56 Labouvie E, Bates ME, Pandina RJ. Age of first use: its reliability and predictive utility. J Stud Alcohol. 1997;58(6):638-43.

57 Johnson TP, Mott JA. The reliability of selfreported age of onset of tobacco, alcohol and illicit drug use. Addiction. 2001;96(8):118798. 